
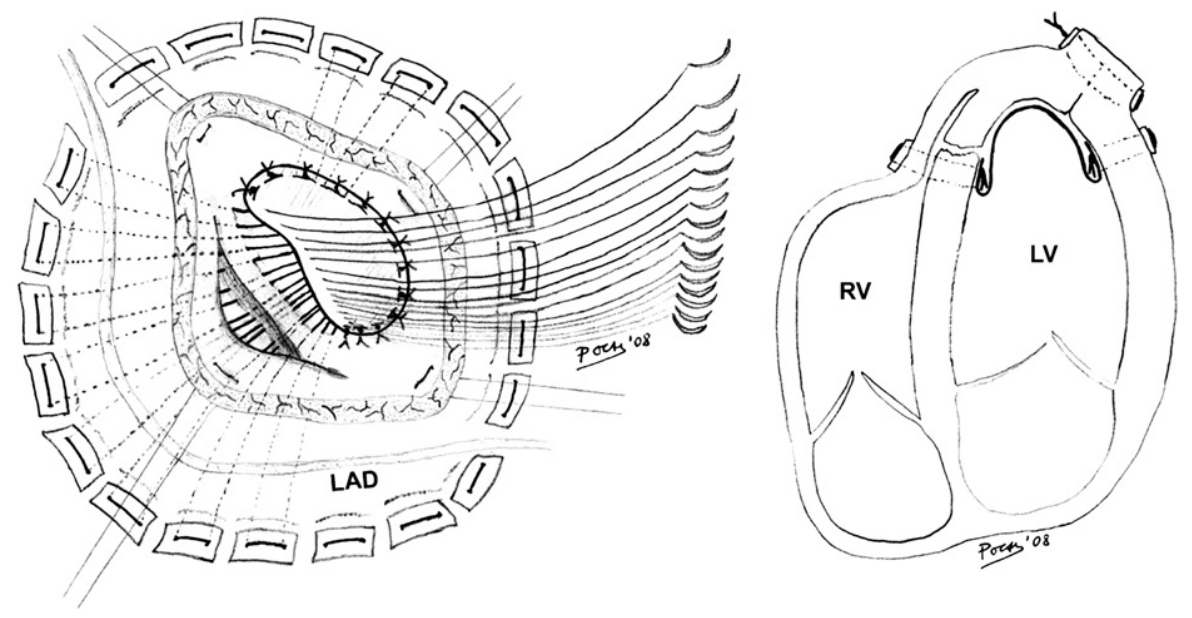

Figure 1. Pledgeted 2-0 polypropylene transmural mattress sutures are passed from outside through the right ventricular free wall and septum, beneath the course of the left anterior descending coronary artery and well posterior to the septal rupture; the remaining stitches are passed in a similar fashion through the left ventricular free wall (left). Sutures are then tied on the patch, and the ventriculotomy is closed. The 4chamber cross-sectional diagram schematically shows juxtaposition of the distal right ventricular free wall over the septal defect (right). LAD, Left anterior descending; $R V$, right ventricular; $L V$, left ventricular.
4. Menon V, Webb JG, Hillis LD, et al., SHOCK Investigators. Outcome and profile of ventricular septal rupture with cardiogenic shock after myocardial infarction: a report from the SHOCK Trial Registry. SHould we emergently revascularized Occluded Coronaries in cardiogenic shocK? $J$ Am Coll Cardiol. 2000;36(suppl A):1110-6.

doi:10.1016/j.jtcvs.2008.01.039

\section{Adverse events in reoperative cardiac surgery: Delineating the typical intraoperative approach To the Editor:}

I read with great interest the recent article by Roselli and colleagues ${ }^{1}$ detailing their review of adverse events during reoperative cardiac surgery. The authors have clearly demonstrated that these adverse events are significantly associated with lapses in preventive strategy and with failure to rescue. As a cardiothoracic anesthesiologist, I am interested in the details of the typical intraoperative setup during the study period (July 2002 to January 2006). I have the following questions:

1. Was blood routinely available in the operating room before incision? If so, how many units?

2. Were external defibrillation pads routinely applied to the chest wall to permit emergency defibrillation as required during sternal entry and/ or mediastinal dissection?

3. Was large-bore intravenous access routinely achieved before skin incision?

4. Was a femoral arterial line frequently placed before sternal incision to ex- pedite femoral arterial cannulation for rescue cardiopulmonary bypass?

I congratulate the authors again on their important contribution. I look forward to their comments about these aspects of preparation for reoperative cardiac surgery.

John G.T. Augoustides, MD, FASE Assistant Professor

Department of Anesthesiology and Critical Care Hospital of the University of Pennsylvania Philadelphia, PA 19104-4283

Financial support: Department of Anesthesiology and Critical Care, Hospital of the University of Pennsylvania.

\section{Reference}

1. Roselli EE, Pettersson G, Blackstone E, Brizzio ME, Houghtaling PL, Hauck R, et al. Adverse events during reoperative cardiac surgery: frequency, characterization, and rescue. $J$ Thorac Cardiovasc Surg. 2008;135:316-23. doi:10.1016/j.jtcvs.2008.02.049

\section{Reply to the Editor:}

We thank Dr Augoustides for his kind comments and inquiries regarding preparation for reoperative cardiac surgery. Cooperation and coordination of the entire team, especially the cardiothoracic anesthesiologist, is critical to success. Owing to space limitations, specific details regarding our typical approach to cardiac reoperations are included in Appendix E4 instead of within the main body of the manuscript. Some of Dr Augoustides' questions are addressed in Appendix E4, but many are not and we thank him for bringing attention to some of the important considerations from an anesthesiologist's viewpoint. Responses to each of his questions are included below:

1. Two units of blood are typically available for all reoperations. For patients undergoing left ventricular assist device explant or open thoracoabdominal aortic aneurysm repair, 4 units are made available.

2. Patients typically have external defibrillator pads placed before skin incision. Additionally, sterile pediatricsized internal defibrillator paddles are available in the room inasmuch as they facilitate access to the partially exposed heart should the external pads not be adequate.

3. Large bore intravenous access is routinely obtained on all patients before incision.

4. We found no correlation between timing (during sternal re-entry or otherwise) or type of adverse event and outcome because so many of these patients were rescued. This experience differs from historical reports of catastrophic sternal re-entry with mortality approaching $50 \%$. This success is in part due to the ability to predict who may have a difficult re-entry and the preparation to compensate for it with rapid institution of cardiopulmonary bypass (CPB). Should the need for emergency institution of CPB arise, methods of preparation vary depending on patient risk. Cross-sectional imaging with computed tomography (either with or without contrast) and 
careful review of cardiac catheterization assists in determining this risk. Preemptive right axillary artery and/ or femoral vessel access or exposure is performed selectively in at-risk patients. Further details of the operative approach are described in Appendix $\mathrm{E} 4$ of the manuscript.

Eric E. Roselli, MD

Department of Thoracic and Cardiovascular Surgery

Cleveland Clinic

Cleveland, Ohio doi:10.1016/j.jtcvs.2008.03.021

\section{Redon drains and underwater seal: The better of two worlds? To the Editor:}

We read with interest the recent article of Gwozdziewicz, Nĕmec, and Steriovsky ${ }^{1}$ describing a technique of chest drainage after cardiac surgery with Redon drains (B. Braun Melsungen AG, Melsungen, Germany)

Five Redon drains are placed in an elaborate fashion into the pericardial space and further drains are added if the pleura are opened and require drainage. The drains are attached to a reservoir under suction of -800 mbar $\left(816 \mathrm{~cm} \mathrm{H}_{2} \mathrm{O}\right)$.

On one hand, we fully agree with the advantages of using Redon drains and add the following to those already cited by the authors: (1) the ease with which these drains are removed, being less painful and requiring minimal or no analgesia, and (2) the fact that only one suture is needed to fix them and no closure is necessary after removal as compared with standard chest tubes. On the other hand, we use only two Redon drains, which correspond to drains 2 and 5 according to Gwozdziewicz's scheme, with number 5 being placed more toward the right ventricle. Occasionally, a third mediastinal Redon drain is added if the patient is at a particular risk for bleeding complications. It is often placed in regard to the culprit site, for example, the left atrium in mitral valve surgery. In case of pleural space drainage, one Redon drain is placed into each pleura as necessary. Moreover, in one of our patients, suction necrosis developed on a venous graft that was in direct contact with one of these Redon drains. This was attributed to the high suction pressure attained by connecting these drains to the reservoir as described in the article. We, therefore, connect the Redon drains to a sterile underwater valve seal system,

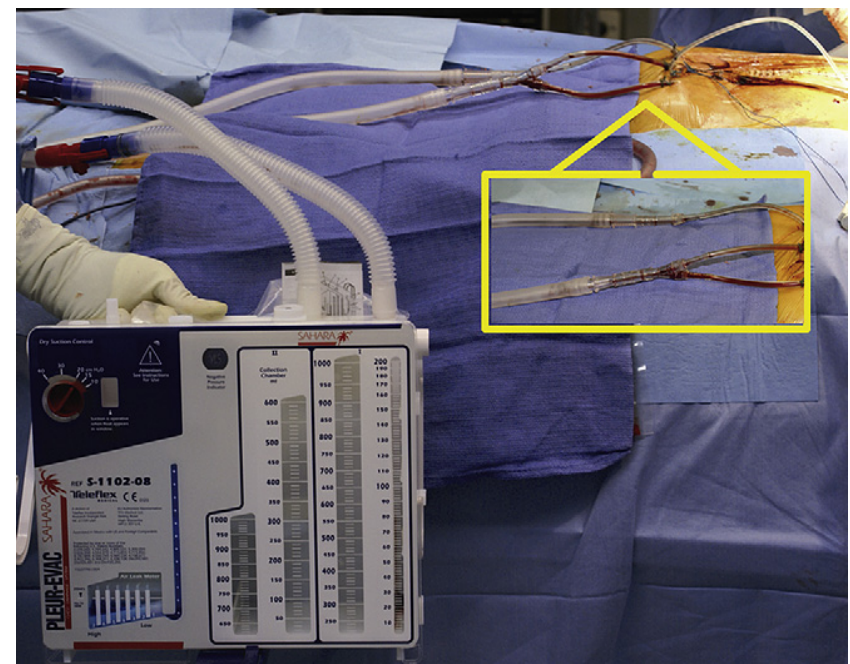

Figure 1. Redon drains attached to an underwater seal system. The suction pressure is regulated at $-20 \mathrm{~cm} \mathrm{H}_{2} \mathrm{O}$. Inset shows connection of drains to system tubing.

Pleur-evac chest drainage unit or Pleurevac Sahara chest drainage dual tube (Teleflex Inc, Research Triangle Park, NC) when the pleura are intact or open, respectively (Figure 1). These systems are completely silent and produce no bubbling sound. They evidently require an external source of suction but control the suction pressure of the Redon drains to around $-20 \mathrm{~cm} \mathrm{H}_{2} \mathrm{O}$, minimizing considerably the risk of a suction lesion on the heart or coronary grafts. We have not encountered such a lesion in our experience with more than 2000 patients in whom this system was applied.

We congratulate the authors on their work and look forward to their feedback on the points we raised.

$$
\begin{array}{r}
\text { Nawwar Al-Attar, FRCS, FETCS, PhD } \\
\text { Richard Raffoul, } M D \\
\text { Patrick Nataf, } M D \\
\text { Bichat Hospital } \\
\text { Paris, France }
\end{array}
$$

\section{Reference}

1. Gwozdziewicz M, Němec P, Steriovsky A. An alternative approach for chest drainage after cardiac surgery: Redon drains. J Thorac Cardiovasc Surg. 2008;135:216-7.

doi:10.1016/j.jtcvs.2008.02.050

\section{Reply to the Editor:}

I greatly appreciate the comments of our French colleagues on our article describing an alternative approach to chest drainage us- ing Redon drains. The main concern they raised was that the high suction used in our system could cause suction lesions on the heart or coronary grafts. They have experienced one case of bypass necrosis resulting from the high suction, but no such complication occurred in our cohort of 4297 patients. I have occasionally observed suction lesions on the heart or even the grafts during reoperations for bleeding when removing a drain that was in direct contact with them, but such lesions always appeared harmless and never led to any problems. In my opinion, the case of bypass necrosis described by Al-Attar, Raffoul, and Nataf was due to the coincidence of direct contact of the drain with a deficient wall of the venous graft.

Their interesting but certainly isolated case report of graft necrosis does not convince me to abandon our technique. I have also seen some isolated complications when using standard $32 \mathrm{~F}$ chest tubes over the years, including graft thrombosis caused by tube compression or even fatal hemorrhagic shock caused by bleeding from the intercostal vessel in the posterior chest wall that was eroded by the chest tube. However, there is no surgical procedure that carries no risks.

When using our technique, care should be taken to avoid direct contact of the Redon drains with the grafts, and this can be achieved by positioning the drains as described in our article: on the bottom of the opened pericardial cavity and leaning against the pericardium rather than lying on the surface of the heart. The only situation in which the drains 